\title{
Preimplantation Genetic Testing (PGT) as Tool for Human Leukocyte Antigens (HLA) Compatible Stem Cell Transplantation
}

\author{
Svetlana Rechitsky and Anver Kuliev* \\ Reproductive Genetic Innovations, Chicago, Illinois, USA
}

${ }^{\star}$ Corresponding author: Dr. Anver Kuliev, Reproductive Genetic Innovations, Chicago, Illinois, 2910 MacArthur Blvd, Chicago, IL 60062, USA; Email: anverkuliev@hotmail.com

Received: November 24, 2021; Accepted: November 30, 2021; Published: November 30, 2021

\begin{abstract}
Preimplantation HLA typing (PGT-HLA) provides patients with an option not only to avoid an inherited risk, but also to establish a pregnancy with an exact HLA match to benefit the affected family member. So HLA typing is now an established PGT indication, to achieve stem cell transplantation treatment of affected siblings in need for compatible transplant. It is also applied as primary indication for cases not requiring preimplantation genetic testing for monogenic disorder (PGT-M), when no HLA-compatible donor is available. The most frequent applications of PGT-HLA were for families with hemoglobinopathy and congenital immunodeficiency siblings, both resulting in total cure when compatible donor was obtained through PGT-HLA. We present here the progress in the application of PGT-HLA tool, based on our practice of 485 PGT-HLA cycles, resulting in obtaining an 117 HLA matched births, providing stem cells for transplantation treatment in 35 different congenital and acquired disorders.
\end{abstract}

Keywords: Preimplantation HLA typing (PGT-HLA), Hemoglobinopathy, Immunodeficiency, Stem cell transplantation, Recombination, Outcome of transplantation treatment with HLA compatible stem cells obtained through PGT-HLA, Probability of obtaining of HLA matched progeny in PGT-HLA

\section{Introduction}

Preimplantation HLA typing (PGT-HLA) was first introduced over twenty years ago to perform bone marrow transplantation treatment of a child with Fanconi anemia (FA) [1,2]. As a totally matched bone marrow is required for transplantation treatment success in this condition, PGT-HLA was an exclusive option, to ensure the birth of an unaffected baby, also to pre-select only those FA free embryos that are also an exact HLA match to the affected child. This was the world's first case of PGT-HLA with the objective of establishing an unaffected pregnancy to yield a potential donor progeny who could provide bone marrow for stem cell transplantation. Since then this approach has been applied for increasing number congenital disorders that require an HLA-compatible donor for bone marrow transplantation [38]. Further it was also applied as a primary indication for cases not requiring mutation testing, but awaiting an HLA-compatible donor [9]. In this paper we will review the progress of application of PGTHLA both as primary indication, as well as together with PGT-M for increasing number of different congenital disorders.

\section{Inherited Disorders for Which PGT-HLA was Performed Concomitantly with PGT-M}

Our experience of PGT- HLA is presented in Table 1, summarizing the results of 485 PGT-HLA cycles performed for 239 patients. A total of 424 HLA matched embryos were identified for transfer (1.46 HLA matched embryos per transfer on the average) in 291 of 485 (68.6\%) cycles, resulting in 125 (43.0\%) clinical pregnancies and birth of 117 healthy HLA matched children, representing stem cell donors for their affected siblings [8]. Among conditions requiring HLA-compatible stem cell transplantation, hemoglobinopathies were one of the most prevalent [10-13], with a total of 188 cycles, allowing detecting and transferring unaffected HLA-matched embryos in 103 (54.8\%) of them. A total of 159 (1.54 on the average) embryos predicted to be either unaffected carriers or normal and HLA-identical to the affected siblings, which is not significantly different from the expectation (Table 2). This resulted in 32 unaffected HLA-identical pregnancies and the birth of 32 healthy children, from whom umbilical cord blood or bone marrow was collected, with the bone marrow transplantation resulting in a successful hematopoietic reconstitution or pending [8].

Similar experience was reported from other large series, including 626 PGT-HLA cycles performed for 312 couples (122 HLA only and 504 with PGT-M), resulting in 128 thalassemia-free children [14,15]. Stem cells of 66 of these children were used for cord blood or bone marrow transplantation, which resulted in successful bone marrow reconstitution in all but two of them (transplantation treatment of the remaining 57 siblings pending).

Severe congenital immunodeficiency (SCID) is another large group of conditions, for which PGT-HLA and stem cell transplantation is required $[8,16]$. Without compatible bone marrow transplantation affected neonates with SCID cannot survive, with the HLA-matched stem cell transplantation improving and completely replenishing the immune system. This group involved a variety of conditions leading to SCID, including incontinentia pigmenti (IP), hyper-IgM type 
Table 1: Preimplantation HLA TESTING (PGT-HLA) WITH AND WITHOUT PGT-M.

\begin{tabular}{|c|c|c|c|c|c|c|c|}
\hline Disease & Gene & \#Patient & \#Cycle & \#Transfers & \begin{tabular}{|c|} 
\#Embryos \\
transferred
\end{tabular} & Pregnancy & Birth \\
\hline HLA genotyping & & 60 & 119 & 73 & 108 & 25 & 22 \\
\hline HLA + ADADENOSINE DEAMINASE DEFICIENCY; ADA & $\mathrm{ADA}$ & 1 & 1 & 1 & 1 & 1 & 1 \\
\hline HLA + ADRENOLEUKODYSTROPHY; ALD & $\mathrm{ABCD} 1$ & 3 & 7 & 2 & 2 & 1 & 2 \\
\hline HLA + CARDIOMYOPATHY, FAMILIAL HYPERTROPHIC, 4; CMH4 & MYBPC3 & 1 & 1 & 1 & 1 & 1 & 1 \\
\hline HLA + GRANULOMATOUS DISEASE, CHRONIC, AUTOSOMAL RECESSIVE; CDG1 & NCF1 & 1 & 3 & 2 & 2 & 1 & 1 \\
\hline $\begin{array}{l}\text { HLA + } \\
\text { DIAMOND-BLACKFAN ANEMIA 1; DBA1 } \\
\text { DIAMOND-BLACKFAN ANEMIA 2; DBA2 } \\
\text { DIAMOND-BLACKFAN ANEMIA 3; DBA3 } \\
\text { DIAMOND-BLACKFAN ANEMIA 5; DBA5 } \\
\text { DIAMOND-BLACKFAN ANEMIA 9; DBA9 }\end{array}$ & $\begin{array}{l}\text { RPS19, } \\
\text { RPS20, } \\
\text { RPS24, } \\
\text { RPL35A, } \\
\text { RPS10 }\end{array}$ & 10 & 17 & 14 & 20 & 8 & 8 \\
\hline $\begin{array}{l}\text { HLA + GLANZMANN THROMBASTHENIA; GT MUSCULAR DYSTROPHY, DUCHENNE TYPE; } \\
\text { DMD }\end{array}$ & $\begin{array}{l}\text { ITGA2B, } \\
\text { DMD }\end{array}$ & 1 & 2 & 2 & 4 & 1 & 0 \\
\hline HLA + MYOTONIC DYSTROPHY 1; DM1 & DMPK & 1 & 2 & 1 & 2 & 1 & 1 \\
\hline HLA + ECTODERMAL DYSPLASIA AND IMMUNODEFICIENCY 1; EDAID1 & IKBKG & 3 & 10 & 8 & 10 & 3 & 4 \\
\hline HLA + EPIDERMOLYSIS BULLOSA DYSTROPHICA, AUTOSOMAL DOMINANT; DDEB & COL7A1 & 1 & 1 & 1 & 1 & 1 & 1 \\
\hline HLA + FANCONI ANEMIA, COMPLEMENTATION GROUP A; FANCA & FANCA & 18 & 56 & 29 & 42 & 14 & 13 \\
\hline HLA + FANCONI ANEMIA, COMPLEMENTATION GROUP C; FANCC & FANCC & 3 & 6 & 6 & 9 & 2 & 2 \\
\hline HLA + FANCONI ANEMIA, COMPLEMENTATION GROUP D2; FANCD2 & FANCD2 & 1 & 3 & 2 & 3 & 1 & 1 \\
\hline HLA + FANCONI ANEMIA, COMPLEMENTATION GROUP F; FANCF & FANCF & 1 & 3 & 2 & 3 & 0 & 0 \\
\hline HLA + FANCONI ANEMIA, COMPLEMENTATION GROUP G; FANCG & FANCG & 2 & 2 & 1 & 2 & 1 & 2 \\
\hline HLA + FANCONI ANEMIA, COMPLEMENTATION GROUP I; FANCI & FANCI & 1 & 2 & 2 & 3 & 0 & 0 \\
\hline HLA + FANCONI ANEMIA, COMPLEMENTATION GROUP J; FANCJ & BRIP1 & 2 & 4 & 4 & 3 & 1 & 1 \\
\hline HLA + GRANULOMATOUS DISEASE, CHRONIC, X-LINKED; CDGX & CYBB & 11 & 16 & 12 & 15 & 7 & 6 \\
\hline HLA + HBB SICKLE CELL ANEMIA; BETA-THALASSEMIA & HBB & 92 & 188 & 103 & 159 & 35 & 32 \\
\hline HLA + IMMUNODEFICIENCY WITH HYPER-IgM, TYPE 1; HIGM1 & CD40LG & 11 & 16 & 10 & 15 & 9 & 8 \\
\hline HLA + KRABBE DISEASE & GALC & 1 & 1 & 1 & 2 & 1 & 2 \\
\hline HLA + MYELODYSPLASTIC SYNDROME; MDS & GATA2 & 1 & 2 & 1 & 1 & 1 & 1 \\
\hline HLA + NEUTROPENIA, SEVERE CONGENITAL, 1, AUTOSOMAL DOMINANT; SCN1 & ELANE & 3 & 5 & 4 & 4 & 4 & 3 \\
\hline HLA + SHWACHMAN-DIAMOND SYNDROME; SDS & SBDS & 4 & 9 & 3 & 3 & 2 & 2 \\
\hline HLA + THROMBOTIC THROMBOCYTOPENIC PURPURA, CONGENITAL; TTP & ADAMTS13 & 1 & 2 & 2 & 4 & 1 & 1 \\
\hline HLA + THROMBOCYTHEMIA 1; THCYT1 & SH2B3 & 1 & 2 & 2 & 2 & 2 & 1 \\
\hline HLA + WISKOTT-ALDRICH SYNDROME; WAS & WAS & 1 & 1 & 0 & 0 & 0 & 0 \\
\hline HLA + POLYCYSTIC KIDNEY DISEASE 1; PKD1 & PKD1 & 1 & 1 & 1 & 2 & 1 & 1 \\
\hline HLA+ PYRUVATE KINASE DEFICIENCY OF RED CELLS & PKLR & 1 & 2 & 1 & 1 & 0 & 0 \\
\hline HLA + HYPER-IgE RECURRENT INFECTION SYNDROME, AUTOSOMAL RECESSIVE & DOCK8 & 1 & 1 & 0 & 0 & 0 & 0 \\
\hline TOTAL & & 239 & 485 & 291 & 424 & $\begin{array}{c}125 \\
43 \%\end{array}$ & 117 \\
\hline
\end{tabular}

Table 2: Chances for detection of disease-free and HLA-matched embryo in preimplantation HLA typing (PGT-HLA).

\begin{tabular}{|l|}
\hline HLA MATCH only $-1 / 4(25 \%)$ \\
\hline Autosomal-recessive or X-linked free + HLA MATCH $-3 / 4 \times 1 / 4=3 / 16(18.75 \%)$ \\
\hline Autosomal-dominant free + HLA MATCH $-1 / 2 \times 1 / 4=1 / 8(12.5 \%)$ \\
\hline
\end{tabular}

1 immunodeficiency (HIGM1), chronic X-linked granulomatous disease (CGD), hypohidrotic ectodermal dysplasia with immune deficiency (HED-ID), Wiscott-Aldrich syndrome (WAS), ataxiatelangiectasia (AT), Type 1 X-linked agammaglobulinemia, Omenn syndrome (OMS), X-linked immunodysregulation, polyendocrinopathy and enteropathy (IPEX), autosomal recessive severe combined immunodeficiency, X-linked severe combined immunodeficiency (SCIDX1), chronic granulomatous disease, and severe congenital neutropenia 1 (SCN1) (Table 1).

The other large group for which PGT-HLA was applied was FA, for which we performed the word's first PGT-HLA mentioned $[1,2]$. This is an autosomal-recessive disorder causing bone marrow failure with increased predisposition to leukemia. Bone marrow transplantation is the only treatment, restoring hematopoiesis in FA patients. However, because any modification of the conditioning is 
too toxic for these patients, leading to a high rate of transplant-related mortality, the HLA-identical stem cell transplantation from a sibling is the only option to avoid late complications due to severe graft-versushost disease (GVH).

Couples at risk for producing a progeny with $\mathrm{FA}$ included carriers of IVS 4+4A-T mutation in the FANCC gene, FANCD2, FANCF, FANCI, FAMCCJ, and FANCA. Overall, 65 unaffected HLA-matched embryos were transferred in 46 of 76 cycles, resulting in 19 unaffected pregnancies and 18 FA-free and HLA-matched neonates, representing potential donors for their older siblings (Table 1).

Of special interest is a case of PGT-HLA involving a consanguineous couple carrying the identical FANCG deletion mutation, who had an affected child with FANCG, requiring stem cell transplantation treatment. Following embryo testing by mutation and linked STR analysis, 2 HLA-matched and disease free (normal and carrier) embryos were transferred, resulting in a twin pregnancy. As couple did not accept confirmatory invasive prenatal diagnosis, a special non-invasive test was developed which allowed confirming unaffected status and HLA matched results for both twins at 15 weeks gestation, which is the world's first case of non-invasive prenatal diagnosis for FA and HLA match [17]. Bone marrow obtained from the twins was transplanted to the affected sibling resulting in a total cure.

Another condition of special interest was a case of PGT-HLA performed for hyperimmunoglobulin M Syndrome (HIGM), which is a rare immunodeficiency characterized by normal or elevated serum IgM levels, with absence of IgG, IgA, and IgE, that results in an increased susceptibility to infections. No radical treatment is available, so PGT-HLA is the only choice for those who lack a suitable HLA match among their relatives. A total of 16 PGT-HLA cycles were performed for 11 couples with HIGM (Table 1), with transfer of 15 unaffected HLA matched embryos in 10 cycles, yielding 9 clinical pregnancies and birth of 8 unaffected HLA matched children, the ideal HLA matched donor for the affected siblings.

PGT-HLA assisted stem cell transplantation is also extremely useful for X-linked hypohidroticectodermal displasia with immune deficiency (HED-ID), which is caused by two dozen different mutations in the IKK-gamma gene (IKBKG, or NEMO). The disease is characterized by susceptibility to microbial and streptococcal infections, dys-gamma-globulinemia, poor polysaccharide-specific antibody responses, and depressed antigen-specific lymphocyte proliferation. To prevent mortality during the first year, bone marrow transplantation is required resulting in a radical treatment, as demonstrated in our experience of 10 PGT-HLA cycles performed for HED-ID patients.

Thus, PGT-HLA provides couples at risk with the option to avoid the affected pregnancy and have a progeny free of the condition and also with an access to the HLA-identical stem cell transplantation through selection and transfer of those unaffected embryos which are also HLA-matched to the sibling. Because the finding of the HLA-identical stem cell donor is the key for achieving the success in stem cell transplantation, a complete cure was achieved in stem cell transplantation in affected siblings.

\section{Preimplantation HLA Typing Without PGT-M}

Preimplantation HLAtyping without testing for a causative gene was first performed for a sporadic Diamond-Blackfan anemia (DBA), requiring bone marrow transplantation treatment [9]. The sole indication in this case was HLA typing, so only a haplotype analysis of the paternal and maternal partners, and affected child was performed in the family prior to PGT-HLA, using a set of polymorphic STR markers located throughout the HLA region. This allowed detecting and avoiding misdiagnosis due to preferential amplification and ADO, potential recombination within the HLA region (see below), and a possible aneuploidy or uniparental disomy of chromosome 6, which may affect the diagnostic accuracy of HLA typing of the embryo. Our experience includes a total of 119 clinical cycles for 60 couples, with pre-selection of 108 HLA-matched embryos for transfer (Table 1). The proportion of embryos predicted to be HLA-matched to the affected siblings was $21.5 \%$, not significantly different from the expected $25 \%$ (Table 2). The transfer of 108 HLA-matched embryos transferred in 73 clinical cycles resulted in 25 singleton clinical pregnancies and 22 HLA-matched children born. These results suggest that testing of an available number of embryos per cycle allows preselecting a sufficient number of the HLA-matched embryos for transfer to achieve a clinical pregnancy and birth of an HLA-matched progeny.

Presented data demonstrate the utility and reliability of PGT-HLA for families having affected children with bone marrow disorders who may wish to have another child. As seen from our data, HLAmatched embryos were preselected and transferred in almost in all cases performed, resulting in clinical pregnancies and the birth of HLA-matched children in almost every second transferred cycle.

\section{Limitations of PGT-HLA and Prospect for Wider Application}

One of important limitations of PGT-HLA is a relatively high frequency of recombination in the HLA region, with a few possible hot spots. Naturally, this may affect the accuracy of PGT-HLA, and the outcome of the whole procedure. In our experience, recombination events were observed both of maternal (3\%) and paternal (1.5\%) origin [8]. Prevalence of recombination was as even higher (6.1\%) when the recombination analysis included siblings requiring HLAcompatible bone marrow transplantation. Recombination detected in a sibling for whom transplantation treatment is required may make PGT-HLA of no use, as the chance of finding of the total HLA match for these siblings is totally unrealistic. Thus, haplotype analysis prior to initiation of the actual cycle is required, so the couples may be informed about their possible options, taking into consideration that only a relatively close match may be detected, warranting discussions with the pediatric hematologist on acceptable HLA profiles.

The other important limitation is a relatively advanced reproductive age of the majority of PGT-HLA patients, which is one of possible explanation that many patients still undergo two or more attempts before achieving an HLA-identical offspring. As concomitant PGT for aneuploidy (PGT-A) appeared useful for improving the reproductive outcome in PGT-HLA $[8,18]$, PGT-A is currently offered as an integral part of PGT-HLA for the patients of advanced 
reproductive age. Our experience shows that reproductive outcome of PGT-HLA combined with PGT-A is significantly higher than those PGT-HLA cycles without PGT-A $[18,19]$.

The usefulness of PGT-A is also obvious for the diagnostic accuracy, as an error in detecting the number of chromosomes 6, in which HLA genes are mapped, may lead to misdiagnosis of HLA profile. Thus, in addition to avoiding chromosomally abnormal embryos from transfer, testing for the copy number of chromosome 6 may become an important requirement for achieving the accuracy of PGT-HLA. Nonetheless, PGT-A will have less utility when only a few embryos are available for testing. To overcome this limitation, two or more cycles are initiated to collect a sufficient number of embryos for analysis. But meaningful batching may not always be possible because some older patients are unable to produce additional oocytes. The possible approach in such cases is to offer these couple the option of HLA testing for the women's younger sister, so that the sister's HLA matched donor oocytes could potentially be used for PGT-HLA cycle. The usefulness of this option was demonstrated in one of our PGT-HLA cases [8], which is the world's first example in using donor eggs from relatives, resulting in obtaining unaffected HLA matched progeny for HLA matched stem cells transplantation, using the PGTHLA cycle involving a sibling as an HLA matched egg donor.

Despite the above limitations, our overall experience of preselection and transfer of the HLA-matched unaffected embryos was possible in $13.7 \%$ of the embryos tested, which is a bit lower than may have been predicted (Table 2). Even with such a relatively moderate success rate, PGT-HLA appeared to be attractive for couples with children requiring HLA-matched bone marrow transplantation, with the number of PGT-HLA requests increasing overall, as the key factor in achieving an acceptable engraftment and survival in stem cell therapy requires is availability of an HLA-identical stem cell transplant $[20,21]$. In fact, due to a small number of children per family, less than one-third of patients has a chance to find an HLA-identical familial donor. The majority for whom no HLA-matched family member exists, the search is extended to haplotype-matched unrelated donors, despite resulting in severe complications.

In conclusion, presented experience demonstrates an increasing attractiveness of PGT-HLA for couples with affected children requiring HLA-compatible stem cell transplantation. Thus, couples at risk of having children with congenital bone marrow disorders could clearly benefit from presently available option of PGT-HLA, allowing not only avoiding the birth of an affected child but also selecting a suitable stem cell donor for their affected siblings.

\section{References}

1. Verlinsky Y, Rechitsky S, Schoolcraft W, Strom C, Kuliev A (2000) Designer babiesare they reality yet? Case report: simultaneous preimplantation genetic diagnosis for Fanconi anemia and HLA typing for cord blood transplantation. Reprod Biomed Online 1: 31. [crossref]

2. Verlinsky Y, Rechitsky S, Schoolcraft W, Strom C, Kuliev A (2001) Preimplantation diagnosis for Fanconi anemia combined with HLA matching. JAMA 285: 3130-3133. [crossref]

3. Rechitsky S, Kuliev A, Tur-Kaspa I, Morris R, Verlinsky Y (2004) Preimplantation genetic diagnosis with HLA matching. Reprod Biomed Online 9: 210-221. [crossref]
4. Van de Velde H, Georgiou I, De Rycke M, Schots R, Sermon K, et al. (2004) Novel universal approach for preimplantation genetic diagnosis of $\beta$-thalassemia in combination with HLA matching of embryos. Hum Reprod 19: 700-708. [crossref]

5. Kahraman S, Karlilaya G, Sertyel S, Karadayi H, Findicli N, et al. (2004) Clinical aspects of preimplantation genetic diagnosis of single gene disorders combined with HLA typing. Reprod Biomed Online 9: 529-532. [crossref]

6. Goussetis E, Konialis CP, Peristeri I, Kitra V, Dimopoulou M, et al. (2010) Successful hematopoietic stem cell transplantation in 2 children with $\mathrm{X}$-linked chronic granulomatous disease from their unaffected HLA-identical siblings selected using preimplantation genetic diagnosis combined with HLA typing. Biol Blood Marrow Transplant 16: 344-349. [crossref]

7. Georgia Kakourou (2018) PGD for HLA (ESHRE study). Reprod Biomed Online, 2018; 36: 4-5.

8. Kuliev A, Rechirsky S, Simpson JL (2020) Practical preimplantation genetic Testing Third Edition. Springer, Nature.

9. Verlinsky Y, Rechitsky S, Sharapova T, Morris R, Tharanissi M, et al. (2004) Preimplantation HLA typing. JAMA 291: 2079-2085.

10. Kuliev A, Rechitsky S, Verlinsky O, Tur-Kaspa I, Kalakoutis G, et al. (2005) Preimplantation diagnosis and HLA typing for hemoglobin disorders. Reprod Biomed Online 11: 362-370.

11. Kuliev A, Packalchuk T, Verlinsky O, Rechitsky S (2011) Preimplantation diagnosis: efficient tool for human leukocyte antigen matched bone marrow transplantation for thalassemia. Thalassemia Rep 1: 1.

12. Kuliev A, Rechitsky S, Verlinsky O (2014) Atlas of Preimplantation Genetic Diagnosis. 3rd Edition. CRS, 2014 Press, Taylor and Francis, London.

13. Kuliev A, Rechitsky S (2016) Preimplnatation HLA typing for stem cell transplantation treatment of genetic and acquired bone marrow failures. Hemat Med Oncol 1: 46-49.

14. Kahraman S (2013) PGD for HLA: Clinical Outcomes of HLA compatible transplantation following PGD. Reprod Biomed Online 26: 9-10.

15. Umay KB, Gavaz M, Kumtepe ÇY, Yelke H, Pirkevi Çetinkaya C, et al. (2019) Successful hemapoietic stem cell transplantation in 62 children from healthy siblings conceived from preimplantation HLA Matching: a clinical experience of 327 cycles. Reprod Biomed Online 39: 13-14.

16. Rechitsky S, Pakhalchuk T, Prokhorovich M, San Ramos G, Verlinsky O, et al. (2018) Preimplantation genetic testing for inherited immunodeficiency. Hematol Transfus Int J 6: 218-220.

17. Rechitsky S, Kuliev A, Leigh D et al. (2020) Single molecule sequencing: a new approach for preimplantation testing and noninvasive prenatal diagnosis confirmation of fetalgenotype. The Journal of Molecular Diagnostics 22: 220-227.

18. Rechitsky S, Kuliev A, Sharapova T, Laziuk K, Ozen S, et al. (2006) Preimplantation HLA typing with Aneuploidy Testing. Reprod BioMed Online 12: 89-100.

19. Rechitsky S, Pakhalchuk T, Goodman A, San-Ramos J, Zlatopolsky Z, et al. (2015) First systematic experience of combined PGD for single gene disorders and/or preimplantation HLA typing with 24-chromosome aneuploidy testing. Fertility of Sterility 103: 503-512. [crossref]

20. Lucarelli G, Andreani M, Angelucci E (2002) The cure of thalassemia by bone marrow transplantation. Blood 16: 81-85.

21. Gaziev J, Lucarelli G (2005) Stem cell transplantation for thalassaemia. Reprod Biom Online 10: 111-115.

\section{Citation:}

Rechitsky S, Kuliev A (2021) Preimplantation Genetic Testing (PGT) as Tool for Human Leukocyte Antigens (HLA) Compatible Stem Cell Transplantation. Mol Genet Res Open Volume 4(3): 1-4. 